\title{
Levels of Household Food Insecurity in Rural Kenya: A Case Study of Kitui West, Lower Yatta and Matinyani Districts
}

\author{
Robinson Ocharo ${ }^{1}$ Wambui Makau ${ }^{2} \quad$ Ayub Gitau $^{3}$ Joseph Mugachia ${ }^{4}$ \\ 1. Department of Sociology, University of Nairobi P.O Box 30197-00100 Nairobi, Kenya \\ 2. Department of Food Science and Nutrition, University of Nairobi P.O Box 30197-00100 Nairobi, \\ Kenya \\ 3. Department of Environmental and Biosystems Engineering, University of Nairobi P.O Box \\ 30197-00100 Nairobi, Kenya \\ 4. Garden Veterinary Services Limited, P.O Box 1042-00618 Ruaraka, Nairobi, Kenya
}

The research was financed by the National Council for Science and Technology, Kenya

\section{Acknowledgements}

We wish to acknowledge the following for their support to this project: First The National Council for Science and Technology (NCST) who funded this project. Secondly The University of Nairobi (UON), Garden Veterinary Services Ltd (GVSL), Kenya Industrial Research Development Institute (KIRDI) and South Eastern Kenya University (SEKU) for logistical support. Third, Government departments at Matinyani, Kitui West and Lower Yatta districts for community mobilization support. Lastly, we wish to thank Amiran Kenya Limited for identification and practical training of project field assistant on greenhouse farming.

DOI: $10.7176 / \mathrm{JEES} / 9-5-06$

Publication date:May $31^{\text {st }} 2019$

\begin{abstract}
.
As a general rule, food security is built on three pillars which are Availability, Accessibility and utilization. The ability to ensure adequate food security hinges on the ability to identify vulnerable households. The degree of vulnerability of an individual, household or group of persons is determined by their exposure to the risk factors and their ability to cope with or withstand stressful situations. This study was a component of a project whose aim was to transfer technology and scale up water harvesting and greenhouse farming in the area with one of its objectives to establish the levels of household food insecurity. Using a proportionate sample of 381 households two major tools were used to collect data. These were a structured interview schedule which was used to collect demographic information and a modified Household Food Insecurity Access Scale (HFIAS) was used to collect information on household food insecurity. In the study it was established that 60.3 percent of the households were getting their food mainly from the farms. Only 39.4 percent relied on the market as their main source of food and 0.3 depended on donations. The households in Kitui had a HFIAS score of 6.86 and falling in the class of severely food insecure with hunger.
\end{abstract}

Keywords: Food Security, Food Insecurity.

\section{Introduction}

Maintaining food security at the country level and household level is still a major challenge for many developing countries. (Zakari et al 2014:1192). As a general rule, food security is built on three pillars which are Availability, Accessibility and utilization. The first pillar is about there being sufficient quantities of food on a consistent basis, the second is about having enough resources to obtain appropriate food and the third is on utilization of food as guided by knowledge of basic nutrition. It is in this background that the World Food Summit of 1996 defined food security as existing "when all people at all times have access to sufficient, safe, nutritious food to maintain a healthy and active life".

Therefore, a household is food secure in a given period if it has enough food to provide its members all the usual meals in a day, for the entire period. Otherwise, the household is food insecure. The ability to ensure adequate food security hinges on the ability to identify vulnerable households. The degree of vulnerability of an individual, household or group of persons is determined by their exposure to the risk factors and their ability to cope with or withstand stressful situations (Zakari et al 2014:1192). It is in this background that this study sought to establish household levels of food insecurity in Kitui West, Lower Yatta and Matinyani Districts. This study was a component of a project whose aim was to transfer technology and scale up water harvesting and greenhouse farming in the area with one of its objectives to establish the levels of household food insecurity.

\section{Methods}

A proportionate sample of 381 households was drawn from Matinyani, Kitui West and Lower Yatta SubLocations. Two major tools were used to collect data. These were a structured interview schedule which was used to collect demographic information and a modified Household Food Insecurity Access Scale (HFIAS) was 
used to collect information on household food insecurity.

In this study the HFIAS was modified in order to accommodate the culture of the locals in terms of food consumption. While a standard HFIAS has nine questions capturing both occurrence and frequency in the domains of anxiety and uncertainty about household food supply, insufficient quality, and insufficient food intake, the one used for this study had eight questions as indicated in the domains below:

Anxiety and uncertainty about the household food supply. In this domain two questions were asked as indicated below.

- In the past 12 months have you ever had problems in satisfying the family food needs?

- In the past 12 months have you ever had to worry that your family might not have enough food?

Insufficient Quality (includes variety and preferences of the type of food) domain with the following two questions:

- In the past 12 months has your family not been able to eat the kind of food they prefer because of scarcity?

- In the past 12 months have you ever had to limit the amount of food your family has to eat because of scarcity?

Insufficient food intake and its physical consequences domain which four questions below:

- In the past 12 months have you and your family ever skipped breakfast because of scarcity?

- In the past 12 months have you and your family ever skipped lunch because of scarcity?

- In the past 12 months have you and your family ever slept hungry because of lack of food?

- In the past 12 months have you and your family ever gone a whole day without food because of scarcity?

Given that in the African context a homestead can be construed to be of several families, the study focused on a nuclear family as a single unit and the head of the family was interviewed.

\section{Results and discussions}

Though Kitui is classified as a semi-arid land it has agricultural potential going by the County's agro-zones. The County is divided into four agro-ecological zones namely; The Semi-Arid farming zone which has potential for agricultural development, Semi-arid ranching areas zones which are less fertile, Arid-Agro-pastoral area which is suitable for grazing and Arid-Pastoral Zones which are suitable for rearing of livestock. The main constraint the Kitui people are faced with is that the farmers in this area rely of rain fed agriculture which requires good timing of rain and use of appropriate seed (drought resistant seeds). Irrigation and water storage for agricultural use are rare practices in Kitui thus increasing vulnerability to drought. However, for those farmers who are doing irrigation and greenhouse farming, the area is promisingly productive as is evident from the photos below.
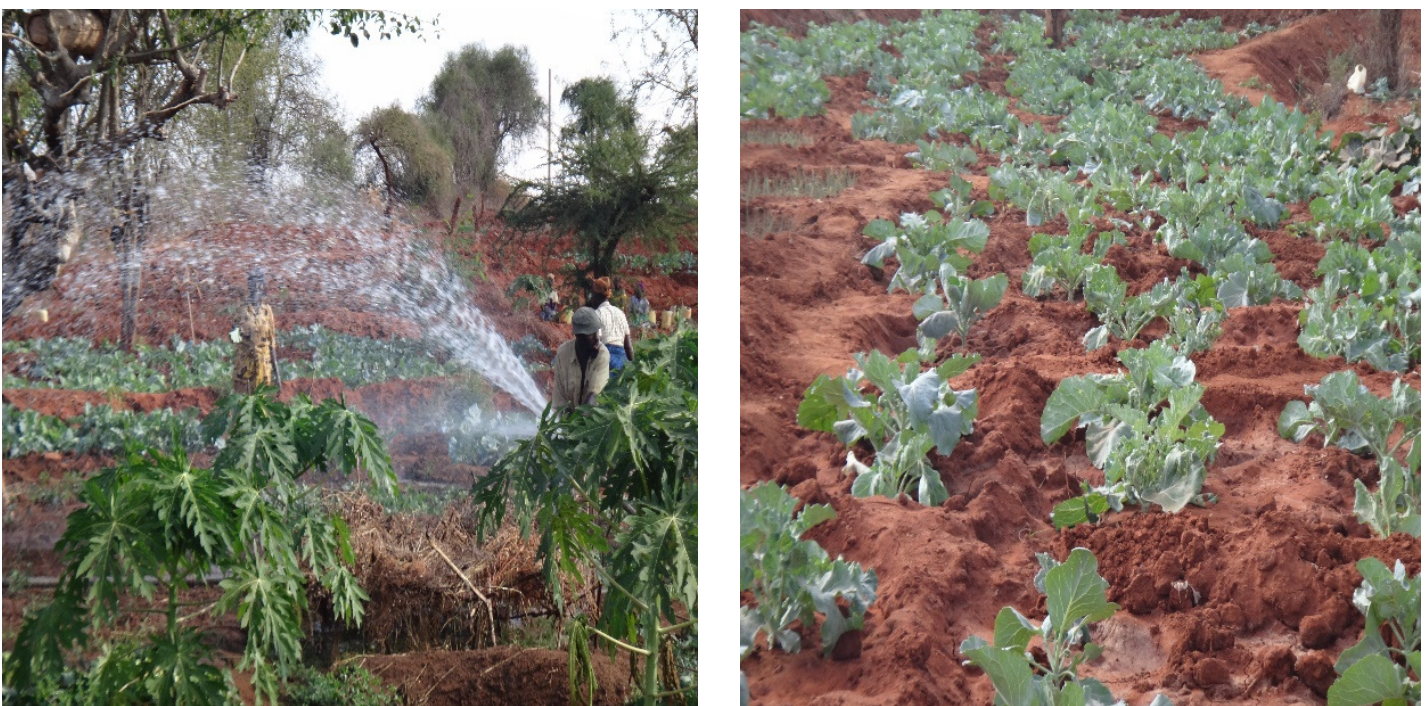

Farmers in Kitui using a diesel water pump to irrigate Kale and pawpaw.

Source: Authors

It is evident that there is irrigation potential in Kitui. However, this will require good practices in water harvesting, storage and use. Going by the green revolution pillar of maximization of space the findings from this study indicate that 87 percent of the households utilized over a half of their land for agriculture.

Apart from type of farming being practiced in Kitui and size of land owned, the study also sought to find 
out the main sources of food for the household and the finding indicated that 60.3 percent of the households were getting their food mainly from the farms. Only 39.4 percent relied on the market as their main source of food and 0.3 depended on donations as indicated in Graph 1 below.

Graph 1: Indicating the main sources of food consumed.

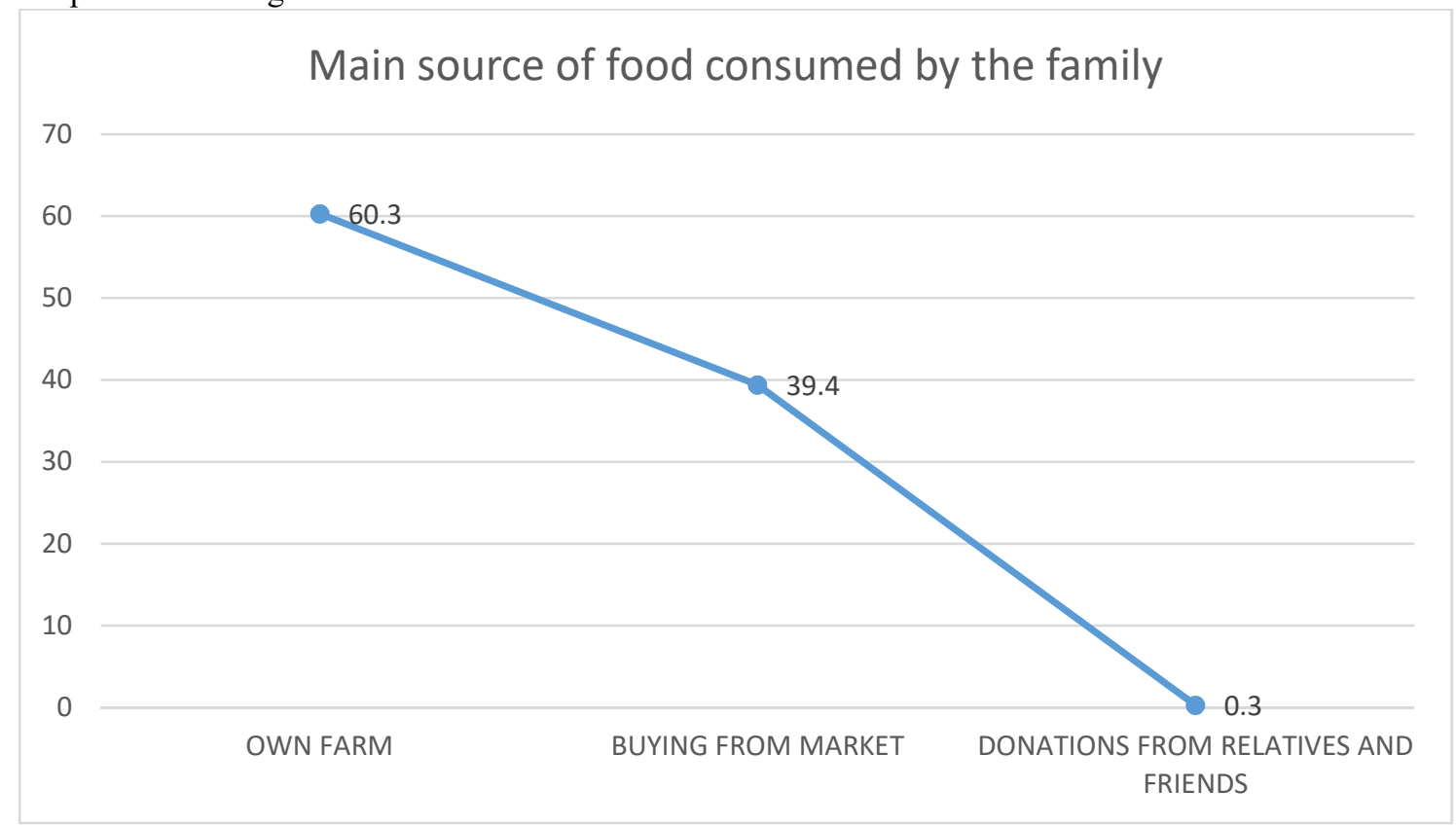

Form the above findings, two things are evident; one is that majority $(60.3 \%)$ of households in Kitui mainly depended on food from their farms and two, it is evident that land utilization was above a half of the total land owned. This at face value paints a picture of a county that is food secure: A state in which "all people at all times have both physical and economic access to sufficient food to meet their dietary needs for a productive and healthy life" (USAID, 1992). This definition has been challenging specifically on how all the dimensions included in it can be empirically proven using appropriate measurement. The Food and Nutrition Technical Assistance Project (FANTA) and its partners did identify a set of questions that have been used in several countries and appear to distinguish the food secure from the insecure households across different cultural contexts. These are the questions contained in the HFIAS and they represent universal domains of the household food insecurity (access) experience and can be used to assign households and populations along a continuum of severity, from food secure to severely food insecure.

In measuring the household food insecurity, each of the eight questions in the scale was asked with a recall period of one calendar year (12 months). The respondents were first asked occurrence questions to establish whether the conditions in the questions happened at all in the past one year (yes or no). For those respondents who answered "yes" to an occurrence question, a frequency-of-occurrence question was asked to determine whether the condition happened rarely (once or twice in a year), sometimes (Once every month) or often (On a weekly basis) in the past twelve months. Further, the hhousehold Food Insecurity Access-related Domains or households experiencing any of the conditions at any level of severity in each domain, was calculated. The formula applied here is [Number household yes to a frequency (rare/sometimes/often) $\div$ Total number of household in that particular frequency $\times 100]$. The results are shown in Graph 2. 
Graph 2: Showing the occurrence of food insecuity conditions at household level

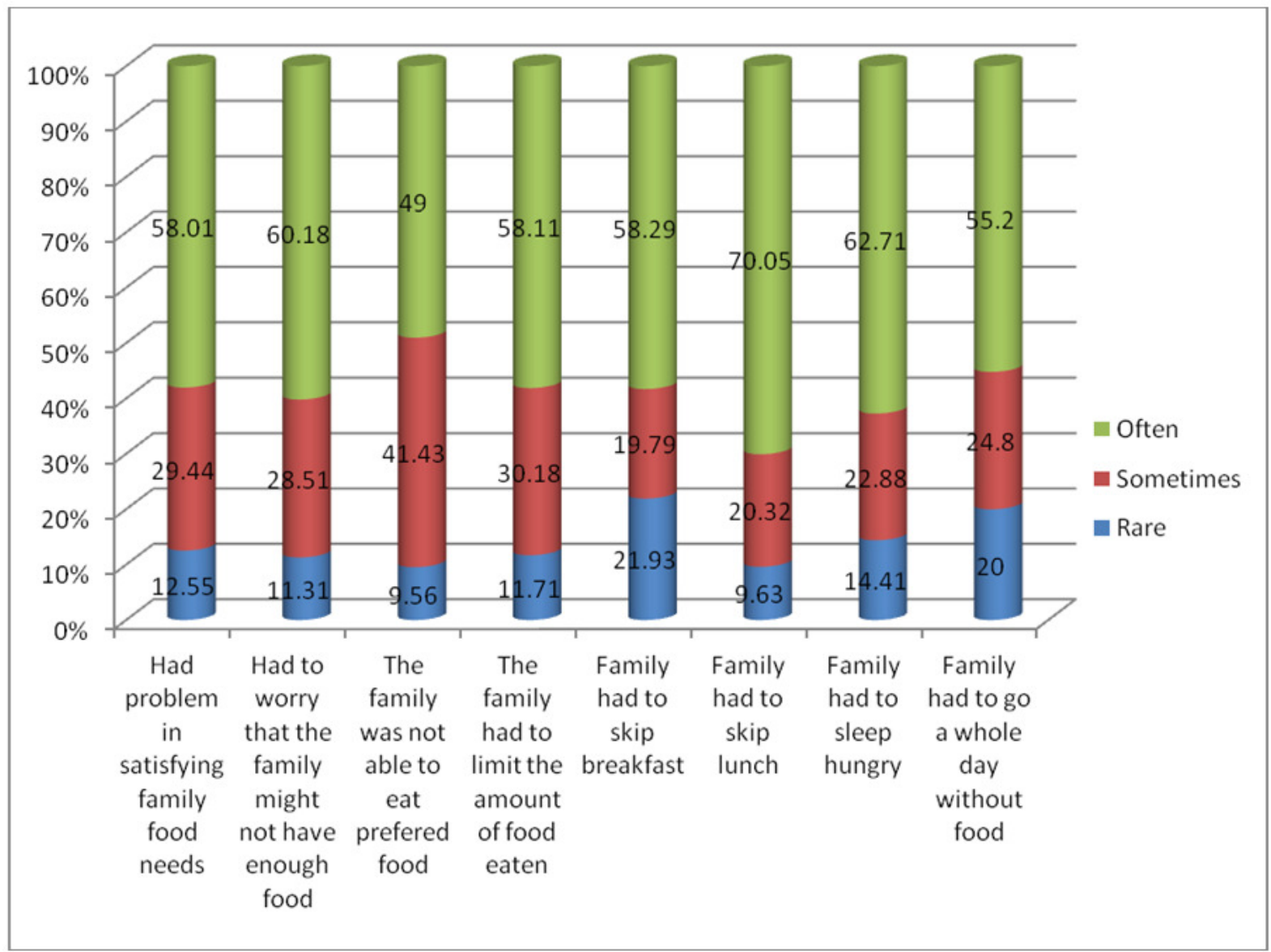

From the above graph it is clear that all households are experiencing food insecurity occurences in all the domains of anxiety and uncertainty, insufficient quality of food and insufficient food intake and its physical consequences.

The highest (84.34\%) reported of occurrence of food insecurity incidences is in the domain of insufficient quality of food. From the study it was established that 53.9 percent of the households reported that they were having three meals a day, 40.1 were having two meals a day and only 6.1 percent were having one meal a day. The second highest $(78.65 \%)$ domain where food insecurity occurrence was reported is that of anxiety and uncertainty. This is collaborated by the findings that 13.8 households reported high production of staple food during the short rains (March - April) and 48.7 percent reported high food production during the long rains (October to November). The domain of insufficient food intake has a score of $61.13 \%$. The explanation to this is one, because for the Kitui people quality of food consumed is not much of a consideration and two, because Kitui receives relief food during drought.

It is clear that the leading frequency was "often" (experiencing the occurances on a weekly basis) with a mean of 59 percent across the domains. The was followed by "sometimes" (experiencing the occurances once every month) which has a mean of 27 percent and the lowest frequency was "rarely" (expereincing the occurances once or twice a year) with a mean of 14 percent.

Based on the data, the average Household Food Insecurity Access Scale score was calculated as follows:

\section{Sum of HFIAS Scores in the sample}

\section{Number of households in the sample}

$=\underline{1542}$

281

\section{Average HFIAS $=\mathbf{5 . 4 9}$}

According to Bickel et al's (2000) HFIAS score and categorization households are classified into food secure, food insecure without hunger, moderately food insecure with hunger, and severely food insecure with hunger as indicated below. 


\begin{tabular}{|c|c|c|c|}
\hline Up to 2.32 & Up to 4.56 & Up to 6.53 & Up to 10 \\
\hline \multirow{3}{*}{ Food Secure } & \multicolumn{3}{|c|}{ Food Insecure } \\
\hline & \multirow{2}{*}{$\begin{array}{l}\text { Food Insecure Without } \\
\text { Hunger }\end{array}$} & \multicolumn{2}{|c|}{ Food Insecure With Hunger } \\
\hline & & $\begin{array}{ll}\text { (Less } & \text { Severe) } \\
\text { "Moderate" } & \end{array}$ & (More Severe) "Severe" \\
\hline
\end{tabular}

Source: Bickel et al (200)

In these scores and categorization, households with a score of up to 2.32 are categorized as food secure, those with a score of up to 4.56 are classified as food insecure without hunger, a score of up to 6.53 are categorized as moderately food insecure with hunger and a score of 6.54 and above are classified as severely food insecure with hunger. An average HFIAS of 5.49 therefore, means that on average the households in Kitui have a score of $5.49 \times 10 / 8=6.86$ and falling in the class of severely food insecure with hunger.

\section{Conclusion}

In this case then, using Bickel et al's (2000) model, the households in Kitui can be described as ones that have adapted a lifestyle of cutting back on meal size or number of meals often, and/or experiences any of the three most severe conditions (running out of food, going to bed hungry, or going a whole day and night without eating), even as infrequently as rarely. The key factor to this condition is the reliability of the sources of food in consumed at household level. In this case 60.3 percent of households indicated that their main source of food was their farms. One explanation as to why the households are severely food insecure with hunger is that the level of agricultural production in the area of study was low despite the fact that 60 percent of the respondents indicated that farming was their main occupation, 63.60 percent owned 3 acres and above of land, and 87 percent used more than half of the land owned doing farming.

\section{References}

Bickel, G., Mark N., Cristofer, P., William, H., and John, C.: (2000) Guide to Measuring Household Food Security, Revised 2000. U.S. Department of Agriculture, Food and Nutrition Service, Alexandria VA.

Coates, J., Anne S. and Paula, B. (2007) Household Food Insecurity Access Scale (HFIAS) for Measurement of Household Food Access: Indicator Guide (v. 3). Washington, D.C.: Food and Nutrition Technical Assistance Project, Academy for Educational

Zakari, S., Ying, 1., and Song, B. (2014) Factors Influencing Household Food Security in West Africa: The Case of South Niger. Sustainability 2014, Vol. 6, Issue 3. Open Access

\section{Appendices}

Appendix 1: Percentage households experiencing condition at any time during the recall period.

\begin{tabular}{|l|l|l|l|}
\hline CONDITION & $\begin{array}{l}\text { NUMBER EXPERIENCING } \\
\text { THE CONDITION }\end{array}$ & FORMULAR & PERCENT \\
\hline $\begin{array}{l}\text { Having a problem in satisfying the family food } \\
\text { needs. }\end{array}$ & 221 & $221 / 281$ X100 & 78.65 \\
\hline $\begin{array}{l}\text { Having to to worry that the family might not have } \\
\text { enough food. }\end{array}$ & 221 & $221 / 281$ X100 & 78.65 \\
\hline $\begin{array}{l}\text { Family not been able to eat the kind of food they } \\
\text { prefer because of scarcity. }\end{array}$ & 251 & $251 / 281$ X100 & 89.32 \\
\hline $\begin{array}{l}\text { Having to limit the amount of food your family } \\
\text { has to eat because of scarcity. }\end{array}$ & 223 & $223 / 281 X 100$ & 79.36 \\
\hline Having skipped breakfast because of scarcity. & 187 & $187 / 281 X 100$ & 66.55 \\
\hline Having skipped lunch because of scarcity. & 187 & $187 / 281 X 100$ & 66.55 \\
\hline Having slept hungry because of lack of food. & 157 & $157 / 281 X 100$ & 55.87 \\
\hline $\begin{array}{l}\text { Having gone a whole day without food because } \\
\text { of scarcity. }\end{array}$ & 156 & $156 / 281 X 100$ & 55.52 \\
\hline
\end{tabular}


Appendix 2: Frequency of condition occurrence

\section{Frequency-of occurrence}

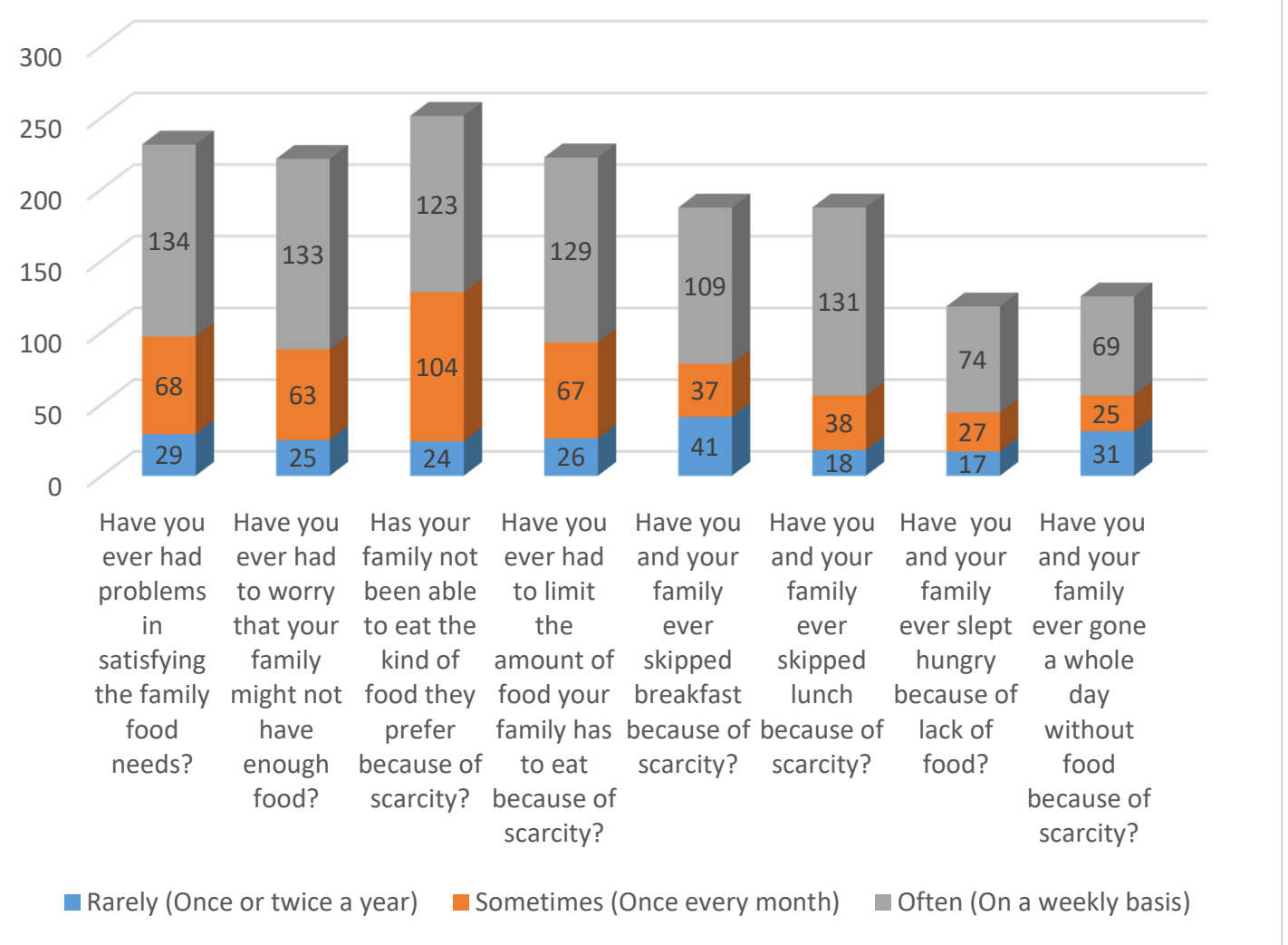

\section{Appendix 3: MAIN OCCUPATION OF THE RESPONDENTS (\%)}

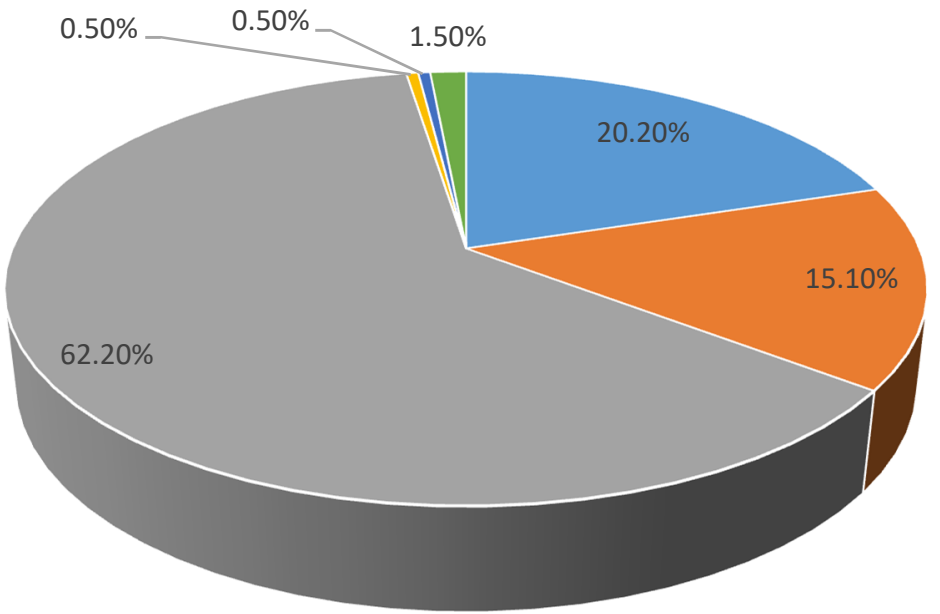

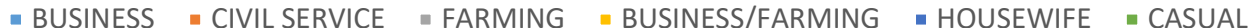




\section{APPENDIX 4: LAND OWNERSHIP IN ACRES}

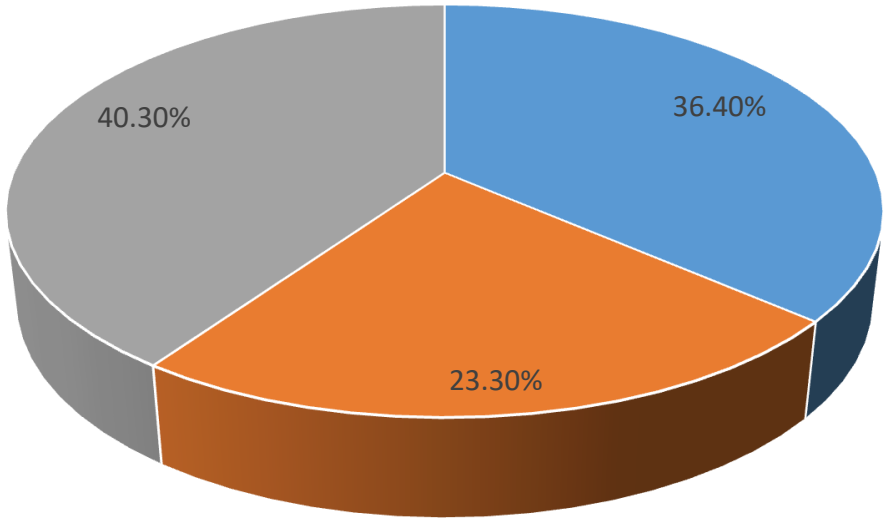

- 1 to 2 - 3 to 4 - Above 4 